\title{
Effect of cyclophosphamide exposure on the migration of primordial germ cells in rat fetuses
}

\author{
Ray B, D’Souza AS, Potu BK, Saxena A \\ Department of Anatomy, Kasturba Medical College, Manipal University, Manipal, Karnataka. \\ biswabina@yahoo.co.in
}

\begin{abstract}
Objectives of the study: Effect of a single dose of cyclophosphamide on migration of the primordial germ cells (PGC), when they are about to reach gonadal ridge was investigated histochemically by staining for alkaline phosphatase. This may throw some light on the fate of gonadal ridge when exposed to the drug itself or its breakdown products such as acrolein, which is present as an environmental pollutant.

Materials and methods: Twelve pregnant Charles foster rats were divided in to control and treatment groups and kept in separate cages. In the experimental group, Cyclophosphamide $20 \mathrm{mg} / \mathrm{kg} / \mathrm{body}$ weight was injected intraperitoneally on day 12 of gestation. Transverse sections of fetuses collected on day 16 of gestation were stained for alkaline phosphatase activity. Outcome of the study was analysed by scanning the photomicrographs and represented by photomicrographs.

Results: An unique finding in experimental group in the gonadal ridge consisted of homogeneously distributed pale staining cells. The gonadal ridge-mesonephros junction showed a single big cluster of the PGC. Under higher magnification, the PGC could be identified by oval or circular shape with well-defined cell membranes and very distinct dark brown staining. There were no signs of degeneration or disintegration of these cells. Conclusions: Cyclophosphamide exposure led to failure of PGC to spread inwards from the gonadal ridge-mesonephros junction giving rise to a situation so far not reported in literature. The presented phenomenon will result in improper development of the gonads leading to infertility in an affected individual in future generation (Fig. 4, Ref. 18). Full Text in PDF www.elis.sk.

Key words: acrolein, cyclophosphamide, environmental pollution, ovary, primordial germ cell.
\end{abstract}

The genital or gonadal ridges develop as paired mesenchymal primordia projecting on each side of the dorsal mesentery, on the medial aspect of the mesonephros. Genital ridges grow as thickenings of coelomic epithelium and condensation of underlying loose mesenchyme along the medial aspect of the mesonephros $(1,2$, $3)$. The mesonephros plays an important role in the development of the indifferent gonads as their somatic cells originate from cellular components of mesonephric glomeruli and tubules $(4,5)$. In addition, Pelliniemi suggested that formation of cellular cords from the coelomic epithelium begin in the human genital ridge at 38 to 39 days of gestation (4). The primordial germ cells (PGC) arise from the epiblast ingressing at the caudal end of the primitive streak (6). With the folding of the embryo underway, the PGC begin their migration along the allantoic and find gut endoderm (6) The PGC continue to divide mitotically during their migration and settlement in the gonad (5). Regardless of the pathway, selective adhesion and survival with directed migration of the PGC are important aspects of gonadal development (7)

Previous studies indicated three phases in the history of the PGC such as the gut, migratory and settlement in the mouse em-

Department of Anatomy, Kasturba Medical College, Manipal University, Manipal, Karnataka

Address for correspondence: B. Ray, MD, Dept of Anatomy, Kasturba Medical College, Manipal University, Manipal, Karnataka.

Phone: +91.820 .2922327$ bryos through days 9 to 1 (8). In the rat embryos, the PGC are known to migrate along the endoderm of the proximal part of the allantois and the gut wall to the gonadal ridge (9).

According to Kemper and Peters (1987), on the postcoital day 10 , the PGC are found in the invaginating visceral yolk sac endoderm and at the base of allantois (10). On the postcoital day 11 , the PGC are mostly found in ventral and lateral gut wall or in the mesenchyme between the gut and future genital ridges. On the postcoital day 12, most of the PGC (94\%) get localized in the mesenchyme or in the future genital ridges.

Whether external factors, like teratogens, can interfere at this phase of development with the migration and proliferation of the PGC or it is totally resistant to such insults needs a thorough probing. Following arrival of the PGC, the study of subsequent changes in the structure of gonads would be pertinent. Subsequent gonadal differentiation and growth during prenatal life with availability of lower number of germ cells also needs to be investigated.

Cyclophosphamide (CP) is a widely used antineoplastic agent. The chemotherapeutic and cytotoxic effects are directly related to the inhibition of DNA alkylation and consequent perturbation of the cell cycle. The active metabolites of $\mathrm{CP}$, phosphoramide mustard and acrolein are alkylating agents, which cross link DNA, thereby interfering with DNA synthesis and RNA transcription (11). Mirkes et al (1984) opinioned that cytotoxic and teratogenic effects of $\mathrm{CP}$ can be related to alterations in the DNA on one hand (phosphoramide mustard) and the structure of proteins on the other (acro- 
lein) (12). CP induced teratogenicity has been studied from various angles but there is paucity of literature on the toxic effects of this agent on early gonadal development. The ultimate number of germ cells present in gonads depends on the proliferation and migration of the PGC to the gonadal ridge. $\mathrm{CP}$, being an antimitotic agent, is known to affect the proliferation of cells $(13,14)$. Hence, it is hypothesized that the agent may interfere with the PGC migration, proliferation during migration and after reaching the gonadal ridge.

The CP exposure to pregnant women is rare, unless on chemotherapy. However, some of the metabolic products of CP like acrolein readily find their way into the atmosphere especially in cities with a high degree of automobile exhaust pollution. Acrolein, a toxic aldehyde is a major combustion product of petroleum and its derivatives (9). It is also present in automobile exhaust, cigarette smoke and is a byproduct of many industrial processes (9). As the people, especially pregnant women, living in cities are continuously exposed to an environment full of such detrimental chemicals, the study becomes relevant in the contemporary industrial world. The present work may give an insight towards the detrimental effects of $\mathrm{CP}$, enabling us to predict the fertility behavior of twenty-first century.

\section{Materials and methods Animals}

12 pregnant Charles foster rats of 200 gm average pre-pregnancy weight and average age of 120 days were used in this study. They were alternately divided in to control and treatment groups and kept in separate plastic cages in noise-free, air-conditioned animal house with temperature maintained at $75^{\circ} \mathrm{F}$ and on a light dark cycle of 12:12 hours with a minimum of $50 \%$ humidity. Rats were fed on diet pellets (Hindustan Lever, Bombay, India), tap water ad libitum, and treated with utmost care. The female rats in their proestrous were caged overnight with males of the same stock (Female : Male = 3:1). Presence of sperms in the vaginal smear on the following morning confirmed the start of gestation and the day was numbered as the day 'zero' of pregnancy.

\section{Experimental procedure}

Administration of the drug: CP was obtained from Khandelwal laboratories, Mumbai, India. A single dose of CP, $20 \mathrm{mg} / \mathrm{kg}$ body weight was dissolved in distilled water and was administered intraperitoneally with the help of a sterile tuberculin syringe to the pregnant rats on day 12 of gestation. Our earlier work suggests that a dose of $20 \mathrm{mg} / \mathrm{kg}$ body weight is sufficient to stop migration of the PGC towards the gonadal ridge, which are present in the wall of yolk sac on the day 12 of pregnancy $(13,14)$. The control rats were administered an equal volume of distilled water. The pregnant rats were sacrificed with overdose of ether anesthesia on day 16 of pregnancy (end of organogenesis period) and the fetuses were collected through laparotomy. Twenty fetuses, three to four apparently healthy looking from each mother rat in both groups were included in the study.

Staining procedure for alkaline phosphatase activity: Transverse sections of fetuses were cut by a sharp safety blade passing through the lumbar region. Caudal portions of the fetuses in the region of the gonadal ridge were fixed in cold acetone at $4{ }^{\circ} \mathrm{C}$. Fetuses were oriented rostrocaudally in the paraffin blocks. Caudal ends of fetuses were sectioned in horizontal plane at $8 \mu$ thicknesses by a rotary microtome and were mounted on the slides. The slides were kept in an incubator at $37{ }^{\circ} \mathrm{C}$ overnight. The sections were deparaffinized, hydrated and stained for alkaline phosphatase activity. Briefly, sections were incubated at $37^{\circ} \mathrm{C}$ for 30 minutes in solution containing $0.8 \%$ sodium $\beta$ glycerophosphate, $2 \%$ sodium barbital, $2 \%$ calcium chloride and $5 \%$ magnesium sulphate .The sections were then washed in distilled water and placed in $2 \%$ cobalt nitrate for 5 minutes. Thereafter all the sections were placed in $2 \%$ yellow ammonium sulphide for 2 minutes and then observed under microscope for black/brown precipitate. The sites of positive alkaline phosphatase activity were sharp, clear and black with a tinge of brown. Positive alkaline phosphatase activity indicates the presence of the enzyme on the plasma membrane, Golgi body, dense granules and the ribosomes of the PGC. The photomicrographs for histological studies were taken with the help of Leitz Orthoplan photomicroscope. The results were compared to control slides.

\section{Results}

Administration of $\mathrm{CP}$ on the day 12 of gestation at a dose of $20 \mathrm{mg} / \mathrm{kg}$ resulted in some unique observations in selected slides. The gonadal ridge consisted of pale staining cells, distributed homogeneously ('arrowhead' in Fig. 1). The size of the gonadal ridge was comparatively smaller ('arrowhead' in Fig. 1) than mesonephros in contrast to control where usually the size of gonadal ridge is seen to be bigger at the reported stage of intrauterine life (14). The gonadal ridge-mesonephros junction showed a single big cluster of the PGC as detected by staining for alkaline phosphatase activity instead of well distributed clusters as seen in the control group ('arrow' in Figs 1, 2, 3). When observed at a higher magnification, the PGC could be identified easily by their shape, size and nature of staining. These were found to be arrested in a

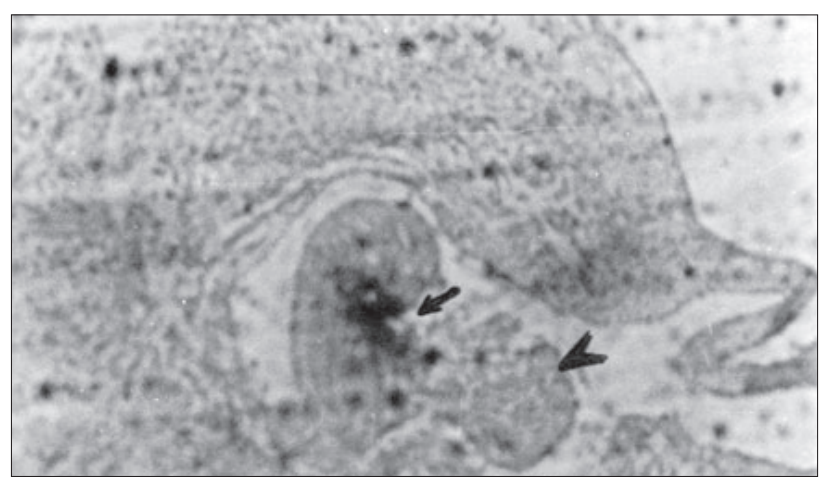

Fig. 1. Photomicrographs of transverse section of 16 day old fetuses stained for alkaline phosphatase activity showing cluster of germ cells, evident by intense alkaline phosphatase activity, conglomerated around a notch (arrow) at the junction of mesonephros and gonadal ridge (arrow head). Gonadal ridge is pale in colour and devoid of germ cells. $X$ 64.51. 


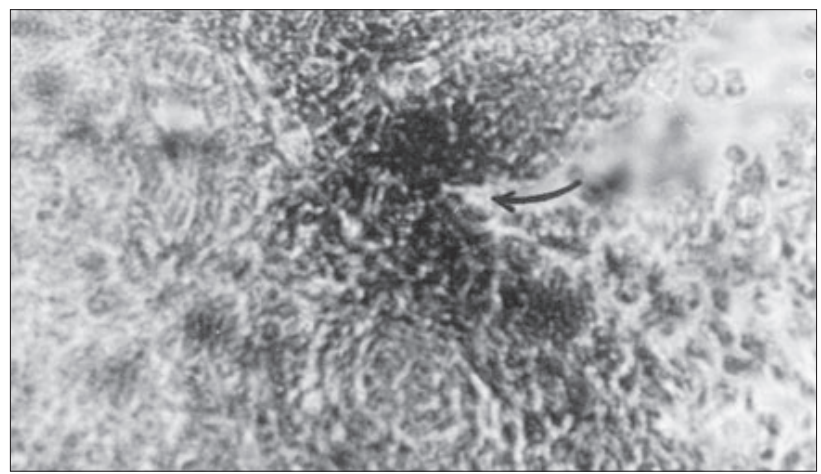

Fig. 2. Photomicrographs of transverse section of 16 day old fetuses stained for alkaline phosphatase activity showing dark blackish-brown coloured cells clustered around a notch (arrow) placed at gonadal ridge-mesonephros junction. The peripheral region shows homogeneous pale stained cells. X 256.

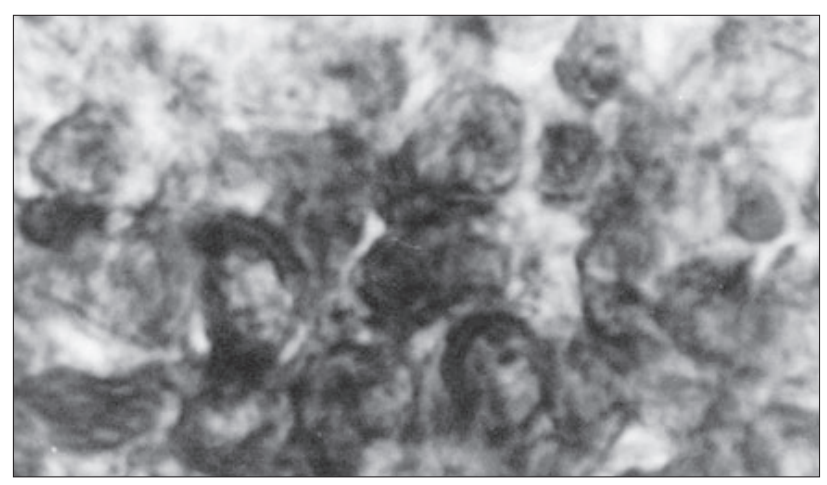

Fig. 3. Photomicrographs of transverse section of 16 day old fetuses stained for alkaline phosphatase activity showing the mesonephrosgonadal ridge junction region. Big size cells of dark blackish-brown colour denoting intense alkaline phosphatase activity on their surface are seen in the cluster (broken line delineates) around the notch (arrows). X409.6.

notched area ('arrow' in Figs 1, 2, 3) at the junction of the mesonephros and the gonadal ridge. The alkaline phosphatase positive cells were of adequate in size, oval or circular in shape with welldefined cell membranes suggesting that these germ cells were healthy. There were no signs of degeneration or disintegration of these cells. The gonadal ridges of control fetuses showed oval or circular dark brown germ cells in well distributed clusters (Fig. 4).

\section{Discussion}

The highlight of the study was a migratory arrest of PGC as observed at the gonadal ridge- mesonephros junction. Various studies indicate that the PGC migration is an active process involving pseudopodia (which contain microfilaments and microtubules) and some lytic enzymes, by which the cells manage to pass through the basal lamina of different tissues, or between the cells within a tissue $(5,7)$.

The migrating PGC always form a close morphological association with the somatic cells including the epithelial cells of the hindgut, mesothelial cells lining the mesentery, genital ridges

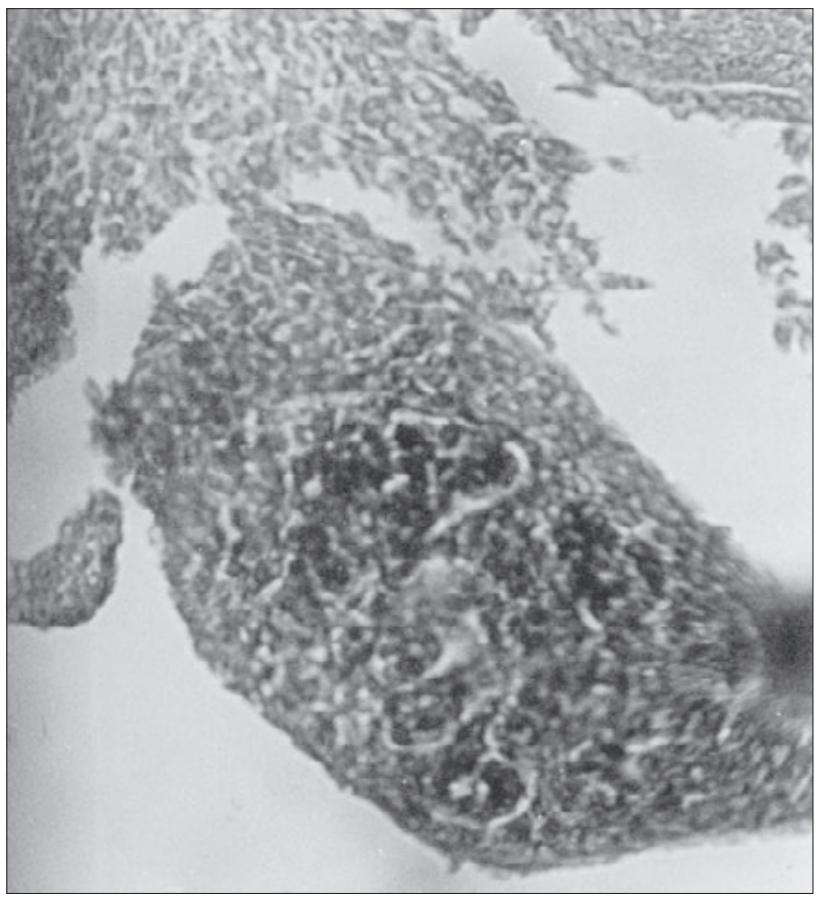

Fig. 4. Photomicrographs of transverse section of $\mathbf{1 6}$ day old fetuses stained for alkaline phosphatase activity. Gonadal ridge from control fetus showing clusters of germ cells with positive alkaline phosphatase activity denoted by blackish-brown colour. Right aspect of the gonadal ridge is in continuity with mesonephros. $X \mathbf{1 6 3 . 8 4}$.

and mesonephros (5). The degree of germ cell-somatic cell contact varies. It is very close in primitive gut where the PGC are completely enveloped by intestinal epithelial cells. Focal and ephemeral in the mesentery where the contact between the two is established through only narrow zone of cellular surfaces. Owing to their amoeboid movements, the PGC quickly shift from one somatic cell to another, suggesting changes in their adhesiveness to various substrates. These may be involved not only in facilitating the migration of germ cells but also in germ cell - somatic cell interactions for providing exogenous substances (gases and nutrients) for metabolism, viability and proliferation of the PGC. The PGC have a simple structural organization and lack sufficient exogenous energy reserves in the form of glycogen and lipids, therefore, are dependent upon somatic cells for transfer of substances $(2,8)$. Alkaline phosphatase activity is specific to PGC and known to be involved in the transport of nutrient substances from adjoining cells $(15,16)$.

On day 12 of gestation, the PGC normally reach close or into the gonadal ridge. In the present study, all the PGC which had succeeded in reaching near the gonadal ridge by 12 th day of gestation were found clustered in a single mass at the gonadal ridge -mesonephros junction. When examined at a higher magnification, the PGC were seen as well formed circular cells with positive alkaline phosphatase activity on their plasma membrane giving deep black brown color. This could be due to administration of $\mathrm{CP}$, which abruptly stopped migration of the PGC deep into the gonadal stroma. This first leg of journey is completed by the PGC 
$637-640$

by their active amoeboid movement and then onwards the germ cells get dispersed in the stroma of the gonadal ridge passively. Proliferation of stromal cells from the mesonephros is believed to be the factor responsible to push the PGC to the most distal part of the gonadal ridge. Byskov and Hoyer (1988) observed a dense cell mass of mesonephric origin at the mesonephros-ovary meeting zone i.e. the region of rete ovari (17). The dense cell mass proliferates not only to add cells to the gonad but also to push the PGC from this point into the gonadal ridge resulting in equidistribution of gonocytes throughout the stroma of the gonad (18). Therefore, we hypothesize that in the present study, the precursor cells gave rise to dense cell mass in the treated specimens proliferated at a slower rate under the influence of CP. Thus the PGC remained clustered at mesonephros-gonad ridge junction (Fig. 1 and 2).

Final shifting of germ cells is apparently regulated by some chemotactic inductor substances produced by the gonadal ridges (5). CP administration might as well have killed the cells responsible for the secretion of such chemotactic substances leading to the failure of migration of the PGC to the gonadal ridge. Therefore, the PGC had altogether failed to spread into the developing gonadal ridge leaving the gonads devoid of gonocytes.

$\mathrm{CP}$ exposure possibly led to the intoxication of the cells proliferating from the mesonephros and also the cells responsible for secretion of chemotactic substances essential for the PGC migration. Therefore, the gonadal dysgenesis was observed where the gonads were devoid of germ cells.

$\mathrm{CP}$ caused a total lack of PGC in the gonadal ridge as a sequel of migratory arrest of PGC at the gonadal ridge- mesonephros junction, which would have resulted in an improper development of the gonads leading to infertility. Although therapeutic CP exposure of pregnant women is rare, some of the metabolic products of CP like acrolein are present as environmental pollutants in petroleum fumes, automobile exhaust, cigarette smoke and byproducts of many industrial processes (9). The present study becomes pertinent in the present day industrial world where pregnant women are being continuously exposed to an environment full of such harmful chemicals. This experimental work may give an insight towards the detrimental effects of $\mathrm{CP}$, enabling us to foresee the fertility pattern of the twenty-first century.

\section{Future directions of research}

Further studies can be done by studying the rate of cell proliferation in the target areas, conducting a live-dead cell assay on PGC and a quantitative assay of level CP or its byproducts in gonadal ridge-mesonephros area.

\section{References}

1. Hamilton WJ, Mossman HW. Human Embryology. Baltimore: Williams and Wilkins, 1972.

2. Merchant H. Rat gonadal and ovarian organogenesis with and without germ cells. An ultrastructural study. Dev Biol 1975; 44: 1-21.

3. Pelliniemi LJ. Fine structure of the human foetal testis. I. The interstitial tissue. Z Zellforsch Mikrosk Anat 1969; 99 (4): 507-522.

4. Wartenberg H. Ultrastructure of Human Gametogenesis and Early Embryogenesis. 61-84. In: Van Blerkom J, Motta PM (Eds). Boston: Kluwer Academic Publishers, 1989 b.

5. Makabe S, Naguro T, Nottola SA et al. Migration of germ cells, development of the ovary, and folliculogenesis. 1-27. In: Familiari G, Makabe S, Motta PM (Eds). Ultrastructure of the Ovary. Boston - Dordrecht: Kluwer Academic Publishers, 1991.

6. Williams PL,Warwick R, Dyson M, Bannister LH (Eds). Grays anatomy of the human body. $38^{\text {th }}$ edition. London: Churchill Livingstone, 1995.

7. Molyneaux K, Wylie C. Regulation of cell-cell adhesion is vital for PGC motility (Primordial germ cell migration. Int J Dev Biol 2004; 48: 537-544.

8. Merchant H, Zamboni L. The fine morphology of mouse primordial germ cells in extragonadal locations. Am J Anat 1973; 137 (3): 299-335.

9. Mohanty C, Singh G, Das BK, Saxena AK. Teratogenicity of Acrolein in rats. J Anat Soc India 2000; 49: 46-48.

10. Kemper CH, Peters PWJ. Migration and proliferation of primordial germ cells in the rat. Teratology 1987; 36: 117-124.

11. Hales BF. Comparison of the mutagenicity and teratogenicity of cyclophosphamide and its active metabolites, 4-hydroxycyclophosphamide, phosphoramide mustard and acrolein. Cancer Res 1982; 42: 3016-3021.

12. Mirkes PE, Greenway JC, Rogers JG, Brundrett RB. Role of Acrolein in Cyclophosphamide Teratogenicity in Rat Embryos in Vitro. Toxicol Appl Pharmacol 1984; 72: 281-291.

13. Ray B, Potu BK. Histological and histochemical studies on the effect of single dose of cyclophosphamide on migration of primordial germ cells of Fetal Charles Foster Rat - A Preliminary Study. Firat Tip Dergisi 2007; 12 (4): 246-250.

14. Ray B, Potu BK. Effect of single dose of cyclophosphamide on development of gonadal ridge in rats - A preliminary study. Pharmacologyonline 2007; 1: 220-231.

15. Gondos B. 239-248. In: Butt WR, Crooke AC, Ryle M (Eds). Gonadotrophins and Ovarian Development. Edinburgh: Livingstone, 1970.

16. Goel S, Sugimoto M, Minami N, Yamada M, Kume S, Imai H. Identification, isolation, and in vitro culture of porcine gonocytes. Biol Reprod 2007; 77: 127-137.

17. Byskov AG, Hoyer PE. The Physiology of Reproduction. 487-540. In: Knobil E, Neill JD et al (Eds). 2nd edition. Vol. 1. New York: Raven Press, 1994.

18. Guraya SS. Cellular and Molecular Biology of Gonadal Development and Maturation in Mammals. Fundamentals and Biomedical Implications. New Delhi, India: Narosa Publishing House, and Heidelberg-Berlin, Germany: Springer Verlag, 1998. 